Journal of Animal and Veterinary Advances 9 (19): 2502-2507, 2010

ISSN: $1680-5593$

(C) Medwell Journals, 2010

\title{
Effects of Desflurane on Oxidant/antioxidant Status of Female Young Versus Old Rat Liver Tissues
}

\author{
${ }^{1}$ Mustafa Arslan, ${ }^{1}$ Berrin Isik, ${ }^{2}$ Mustafa Kavutcu and ${ }^{3}$ Omer Kurtipek \\ ${ }^{1}$ Department of Oral and Maxillofacial Surgery, Faculty of Dentistry, \\ Gazi University, Ankara, Turkey \\ ${ }^{2}$ Department of Medical Biochemistry, Faculty of Medical, \\ University of Gazi, Ankara, Turkey \\ ${ }^{3}$ Department of Anesthesiology and Reanimation, Faculty of Medical, \\ University of Gazi, Ankara, Turkey
}

\begin{abstract}
Abstrat: Volatile agents are known to have an adverse effect on hepatic antioxidant defense mechanism as well as accelerating peroxidation. As a result, volatile agents are assumed to cause some structural changes in hepatic tissues. Halothane hepatotoxicity has been studied extensively but desflurane not clarified yet. In this research, we aim to determine the presence of oxidative stress and antioxidant activity in the liver tissue samples of the rats with anaesthetized desflurane. The study involved 40 female Wistar Albino rats. The rats were divided into two groups [(Group I, $\mathrm{n}=20$ ): Young female desflurane group (Group I-YFD, $\mathrm{n}=10$ ); Young female control group (Group I-YFC, $\mathrm{n}=10$ ), (Group II, $\mathrm{n}=20$ ): Old female desflurane group (Group II-OFD, $\mathrm{n}=10$ ); Old female control group (Group II-OFC, $\mathrm{n}=10$ )]. The anaesthesia procedure was conducted with the groups of rats in a transparent plastic container. Desflurane was administered at $6 \%$ volume inspiratory concentration, $6 \mathrm{~L} \mathrm{~min}{ }^{-1}$ in $100 \% \mathrm{O}_{2}$ for $2 \mathrm{~h}$. The control groups were not subjected to any procedures. Accordingly, Thiobarbutiric Acid-Reactive Substances (TBARS) level and Glutathione-S Transferase (GST), Superoxide Dismutase (SOD) and Nitric Oxide Synthase (NOS) enzyme activity were studied in the liver tissue samples of the rats to determine the presence of oxidative stress and antioxidant activity. Glutathione-S transferase, SOD, NOS enzyme activity and TBARS level after desflurane anesthesia was significantly higher in Group II-OFD than in Group I-YFD and Group II-OFC. Oxidative stress in the liver tissue samples of the old rats more than young rats after desflurane administration.
\end{abstract}

Key words: Oxidative stress, liver tissue, rat, desflurane, GST, SOD, NOS, TBARS

\section{INTRODUCTION}

Volatile agents have been frequently used in general anesthesia practice without complications. However, they still have adverse affects on various body systems. Although, most of these effects are minimal and reversible, occasionally, fatal complications such as fulminant hepatitis may occur.

Hepatotoxicity with halothane inhalation has been studied extensively (Cote and Bouchard, 2007). Desflurane associated hepatitis is not well documented but hepatotoxicity cases and death have been reported associated with desflurane (Martin et al., 1995; Berghaus et al., 1999; Tung et al., 2005; Chin et al., 2008).

Volatile agents are known to have an adverse effect on hepatic antioxidant defense mechanism as well as accelerating peroxidation (Durak et al., 1996a). As a result, volatile agents are assumed to cause some structural changes in hepatic tissues (Carbonell et al., 2000).

Oxidative Stress (OS) arises due to an imbalance between the production and elimination of free oxygen radicals that are generated during aerobic metabolism and consumed endogenously.

The role of anesthetic agents in OS production or protection against the harmful effects of free oxygen radicals has been a topic of significant studies (Durak et al., 1996a; Carbonell et al., 2000; Durak et al., 1997, 1999; Allaouchiche et al., 2001). The studies have shown that halothane or desflurane have negative effects on the antioxidant system of various tissues (Durak et al., 1997, 1999; Schneemilch et al., 2005). In several studies, lowered, increased or unchanged OS were observed (Durak et al., 1999; Allaouchiche et al., 2001; Schneemilch et al., 2005; Allan et al., 1987; Xu et al.,

Corresponding Author: Mustafa Arslan, Department of Oral and Maxillofacial Surgery, Faculty of Dentistry, Gazi University, Emek 06510, Ankara, Turkey 
1998). In this respect, literature reveals conflicting results on the effects of this anesthetic agent. In aerobic organisms, it is possible to evaluate OS by studying Thiobarbutiric Acid-Reactive Substances (TBARS) and Nitric Oxide Synthase (NOS) levels and antioxidant defense systems based on superoxide levels such as Superoxide Dismutase (SOD), Glutathione Peroxidase (GSHPx), Glutathione-S Transferase (GST), Catalase (CAT) and glutathione reductase (Richard et al., 1992; Sessa, 1994; Bezerra et al., 2004; Prabhu et al., 2004).

The aim of the research is to determine the presence of OS and antioxidant activity in the liver tissue samples of the rats accordingly, NOS, SOD, GST activity and TBARS levels.

\section{MATERIALS AND METHODS}

The study was performed upon the approval of Gazi University Experimental Animals Ethics Committee and Erciyes University Medical School Ethics Committee in Erciyes University Experimental and Clinical Research Center (DEKAM).

The study involved 40 female Wistar Albino rats ( 20 young ( 5 months old) and 20 old ( 12 months old)) with a weight of $175-210 \mathrm{~g}$ raised under the same conditions. The rats had free access to food and water until $2 \mathrm{~h}$ before anaesthesia procedure and were kept in a room at $20-24^{\circ} \mathrm{C}$ with a rhythm of $12 \mathrm{~h}$ light and $12 \mathrm{~h}$ darkness. Before the study was started, anaesthetic gas vaporisers were calibrated. Anaesthetic gase was set at a Minimum Alveolar Concentration (MAC) of 1 and desflurane 6\% vol as recommended by Eger and Johnson (1987) and Haelewyn et al. (2004) was administered.

The anaesthesia procedure was conducted with the groups of rats (per group) in a transparent plastic container of $40 \times 40 \times 70 \mathrm{~cm}$ in size. The container which allowed for observation of the rats was connected to a half open anaesthesia machine (AMS, Senior 425) with static hoses. The anaesthetic gases were released into the container in $100 \% \mathrm{O}_{2}$.

The rats were divided into two groups. Then each group was further divided into two subgroups for each volatile anaesthetic agent used. The control groups were not subjected to any procedures. I-Group $\mathrm{I}, \mathrm{n}=20$ :

- Young female desflurane group (Group I-YFD, $\mathrm{n}=10$ )

- Young female control group (Group I-YFC, $\mathrm{n}=10$ )

II-Group II, $\mathrm{n}=20$

- Old female desflurane group (Group II-OFD, $\mathrm{n}=10$ )

- Old female control group (Group II-OFC, $\mathrm{n}=10$ )
Desflurane (Suprane ${ }^{\circledR}$, Eczacibasi, Istanbul, Turkey) was administered at $6 \% \mathrm{vol}$ inspiratory concentration, $6 \mathrm{~L} \mathrm{~min}^{-1}$ in $100 \% \mathrm{O}_{2}$ for $2 \mathrm{~h}$. After anaesthesia procedure, the abdomens of the rats were opened immediately after the exposure procedure was completed and intraabdominal blood samples were obtained from the abdominal aorta. All the rats were then euthanased following $50 \mathrm{mg} \mathrm{kg}^{-1} \mathrm{ketamin}$ administration. Preserving the tissue integrity, liver biopsy samples were obtained paying attention not to traumatize.

Biochemical analysis: The liver tissues were first washed with cold deionized water to discard blood contamination and then homogenized in a homogenizator. Measurements on cell contest require initial preparation of the tissues. Preparation may involve grinding of the tissue in a ground glass tissue blender using a rotor driven by a simple electric motor. The homogenizator as a tissue blender similar to the typical kitchen blender is used to emulsify and pulverize the tissue (Heidolph Instruments GMBH and CO KG Diax 900 Germany $^{\circledR}$ ) at $1000 \mathrm{U}$ for about $3 \mathrm{~min}$. After centrifugation at $10,000 \mathrm{~g}$ for about $60 \mathrm{~min}$, the upper clear layer was taken. In this fraction, Total Nitric Oxide Synthase (T-NOS) activity and Nitric Oxide (NO) pool $\left(\mathrm{NO}+\mathrm{NO}_{2}{ }^{-}\right)$were measured as described, respectively (Bucala et al., 1991; Ignarro et al., 1987). NOS activity method was based on the diazotization of sulfanilic acid by nitric oxide at acid $\mathrm{pH}$ and subsequent coupling to N-(1-napthyl-ethylene diamine) which is the modification of a previous study (Bucala et al., 1991; Ignarro et al., 1987; Durak et al., 2001). The analysis scheme of the NOS activity measurement method has been described in a previous study (Durak et al., 2001). Measurement of the $\mathrm{NO}$ pool (mainly consisting of $\mathrm{NO}+\mathrm{NO}_{2}{ }^{-}$) is also based on the same chemical reaction in which to a greater extent Nitric Oxide (NO) and to a lesser extent Nitrite anion $\left(\mathrm{NO}_{2}{ }^{-}\right)$but not Nitrate anion $\left(\mathrm{NO}_{3}{ }^{-}\right)$ give a diazotization reaction with sulfanilic acid. The absorbance of complexone formed with N-(1-napthylethylene diamine) reflects the sum of $\mathrm{NO}$ and $\mathrm{NO}_{2}{ }^{-}$levels in the reaction medium which is termed the $\mathrm{NO}$ pool in the present study. In this method, sodium nitroprusside is used as the chemical standard and the reaction scheme given for the NOS activity measurement, except for the incubation of the sample with arginine is followed. The thiobarbutiric acid-reactive substances levels were determined in the same supernatant fraction by using the thiobarbituric acid method of Van-Ye et al. (1993) and were expressed in nmol $\mathrm{mg}^{-1}$ protein.

A part of the homogenate was extracted in ethanol/chloroform mixture $(5 / 3 \mathrm{v} / \mathrm{v})$ to discard the lipid fraction which caused interferences in the activity 
measurements of total superoxide dismutase (T-SOD) and total Glutathione-S Transferase (T-GST). After centrifugation at $10.000 \times \mathrm{g}$ for $60 \mathrm{~min}$, the upper clear layer was removed and used for the analyses.

The SOD activity method is based on the measurement of absorbance increase at $560 \mathrm{~nm}$ due to

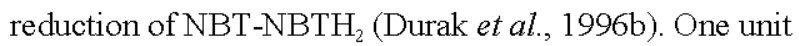
of SOD activity was defined as the enzyme protein amount causing $50 \%$ inhibition in $\mathrm{NBTH}_{2}$ reduction rate and the results were expressed in $\mathrm{U} \mathrm{mg}^{-1}$ protein.

The GST activity was assayed using the procedure described by Habig et al. (1974) using 1-Chloro-2,4Dinitrobenzene (CDNB) as a substrate in Ultraviolet (UV by sequential addition of $0.1 \mathrm{M}$ phosphate buffer, $\mathrm{pH} 6.5$ $(1.5 \mathrm{~mL})$, enzyme preparation as above $(0.1 \mathrm{~mL}), 50 \mathrm{mM}$ of reduced GSH solution in buffer $(0.2 \mathrm{~mL})$ and $25 \mathrm{mMCDNB}$ solution in ethanol $(0.15 \mathrm{~mL})$ ( $2 \mathrm{~mL}$ final volume of the routine incubation mixture). Enzyme activity was determined by continuously monitoring the change in absorbance at $340 \mathrm{~nm}$ for $3 \mathrm{~min}$ at $25^{\circ} \mathrm{C}$ with a Shimadzu UV-1601 spectrophotometer and results were expressed in $\mathrm{mI} \mathrm{U} \mathrm{mg}{ }^{-1}$ protein. Protein amounts were measured as described by Lowry et al. (1951).

Statistical analyses: The statistical analyses were performed with SPSS 12.0 software program and $\mathrm{p}<0.05$ was considered statistically significant. The findings were expressed as mean \pm Standard Deviation (SD). The data were evaluated with Kruskal-Wallis variance analysis. The variables with significance were evaluated with Bonferroni corrected Mann-Withney U test.

\section{RESULTS AND DISCUSSION}

The mean weight of the young female rats and old female rats were similar for all the groups. TBARS levels and GST, SOD, NOS enzyme activity are shown in Table 1, Fig. 1-4. The mean TBARS levels of Group II-OFD was significantly higher than those of Group II-OFC and Group I-YFD ( $p<0.0001 ; p<0.0001)$ (Table 1, Fig. 1). Similarly, the mean GST enzyme activity of Group II-OFD was significantly higher than those of Group II-OFC and Group I-YFD ( $<<0.0001 ; \mathrm{p}<0.0001$ ), (Table 1, Fig. 2).

The increases of SOD enzyme activity in Group IIOFD was significantly higher than those of Group II-OFC and Group I-YFD ( $<<0.0001 ; p<0.0001)$ (Table 1, Fig. 3). Similarly, the mean NOS enzyme activity of Group II-OFD was significantly higher than those of Group II- OFC and Group I-YFD ( $\mathrm{p}=0.001 ; \mathrm{p}=0.009$ ) (Table 1, Fig. 4). The findings of the study indicated that desflurane treated old rat groups had higher GST, SOD, NOS enzyme activity and TBARS levels than the young groups did
Table 1: Mean \pm SD values of GST ( $\left.\mathrm{mI} \mathrm{U} \mathrm{mg}^{-1}\right)$ SOD $\left(\mathrm{U} \mathrm{mg}^{-1}\right)$, NOS (mI $\mathrm{U} \mathrm{mg}^{-1}$ ), enzyme activities and TBARS (nmoL $\mathrm{g}^{-}$) levels in rat liver tissues (Mean \pm SD)

\begin{tabular}{lllll}
\hline Enzymes & $\begin{array}{l}\text { TBARS } \\
\left(\mathrm{nmoL} \mathrm{mg}^{-1}\right)\end{array}$ & $\begin{array}{l}\text { GST } \\
\left(\mathrm{mL} \mathrm{U} \mathrm{mg}^{-1}\right)\end{array}$ & $\begin{array}{l}\text { SOD } \\
\left(\mathrm{U}^{-1} \mathrm{mg}\right)\end{array}$ & $\begin{array}{l}\text { NOS } \\
\left(\mathrm{mLUmg}^{-1}\right)\end{array}$ \\
\hline Group I-YFC & $0.99 \pm 0.26$ & $8.59 \pm 1.52$ & $5.05 \pm 2.42$ & $4.39 \pm 1.51$ \\
Group I-YFD & $1.17 \pm 0.49$ & $8.90 \pm 1.28$ & $7.00 \pm 0.26$ & $5.57 \pm 1.38$ \\
Group II-OFC & $0.98 \pm 0.45$ & $9.06 \pm 1.69$ & $6.53 \pm 2.12$ & $5.46 \pm 1.51$ \\
Group II-OFD & $2.66 \pm 0.49^{*+}$ & $11.70 \pm 2.32^{*+}+$ & $11.12 \pm 1.26^{*+}$ & $6.40 \pm 1.76^{*+}$
\end{tabular}

TBARS, Thiobarbutiric Acid Reactive Substances; GST, Glutathione STransferase; SOD, Superoxide Dismutase; NOS, Nitric Oxide Synthatase; $* \mathrm{p}<0.05$ when compared to group I-OFC,$+\mathrm{p}<0.05$ when compared to group I-YFSD

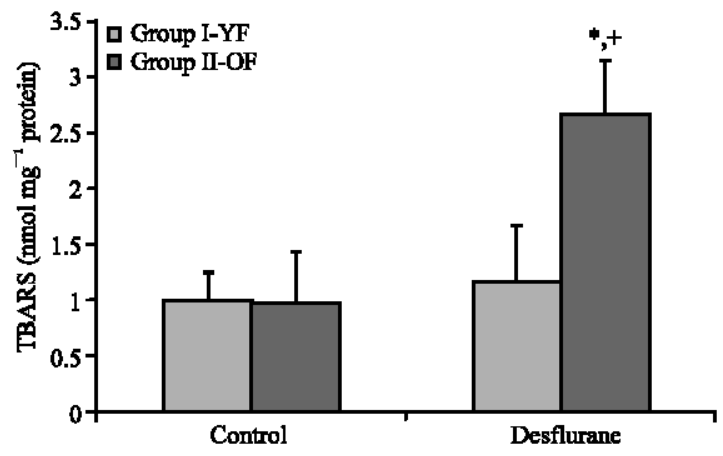

Fig. 1: The TBARS levels of the groups. Values are mean \pm SD. ${ }^{*} \mathrm{p}<0.05$, when compared to Group I$\mathrm{OFC},+\mathrm{p}<0.05$ when compared to Group I- YFD

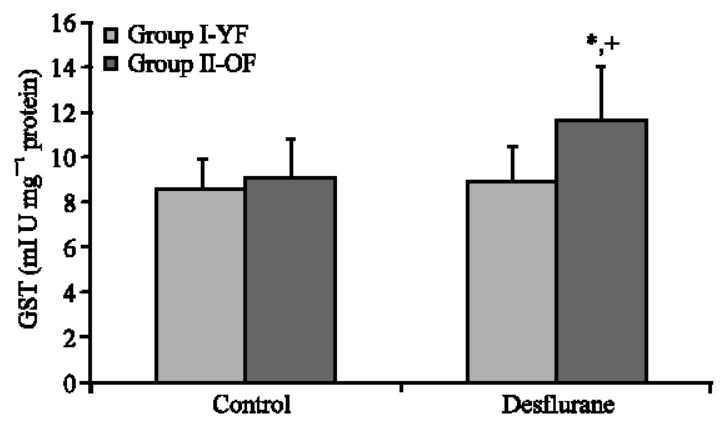

Fig. 2: The GST levels of the groups. Values are mean $\pm \mathrm{SD} .{ }^{*} \mathrm{p}<0.05$, when compared to Group I$\mathrm{OFC}+\mathrm{p}<0.05$ when compared to Group I- YFD

clearly suggesting that desflurane tends to create more OS in old rats. Volatile agents are known to have an adverse effect on hepatic antioxidant defense mechanism (Durak et al., 1996a). The role of desflurane in OS production or protection against the harmful effects of free oxygen radicals has not been researched intensively. But desflurane associated hepatotoxicity cases and death have been reported (Martin et al., 1995; Berghaus et al., 1999; Tung et al., 2005; Chin et al., 2008).

The most recent report on hepatotoxicity associated with desflurane is that of Chin et al. (2008) who reported the case 53 years old female patient. The other Tung et al. 


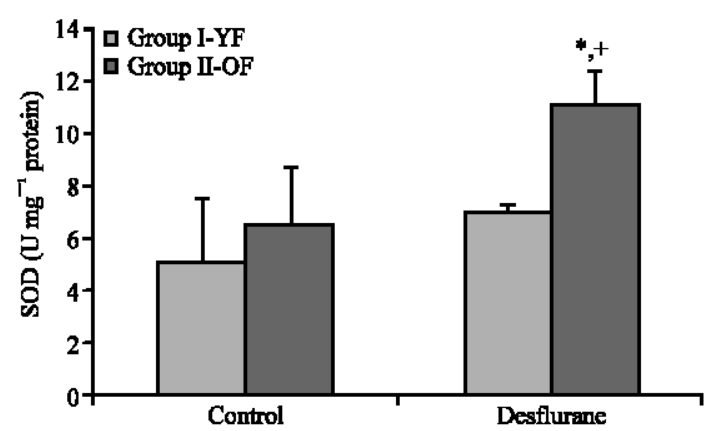

Fig. 3: The SOD levels of the groups. Values are mean \pm SD. ${ }^{*} \mathrm{p}<0.05$, when compared to Group I$\mathrm{OFC}+\mathrm{p}<0.05$ when compared to Group I- YFD

(2005) who reported the case an 81 years old female patient. Martin et al. (1995) reported a 65 years old female patient in whom hepatitis development was attributed to desflurane. Likewise, Berghaus et al. (1999) reported desflurane associated hepatitis in an obese 37 years old female patient.

The studies have shown that halothane or desflurane have negative effects on the antioxidant system of various tissues (Durak et al., 1996a, 1997; Allaouchiche et al., 2001). In the previous study (Arslan et al., 2010), we show that desflurane application did not create any changes in young male rats but it cause mild to moderate degree of hepatic injury in old male and female rats at higher incidences than in young female rats. For that reason in this research we investigate OS induced from desflurane on female rats. Certain biochemical tests guide in determining oxidative stress or antioxidant activity in the liver tissue samples. Oxygen radicals produced at the cellular level are detoxified by $\mathrm{SOD}$ and the final product is $\mathrm{H}_{2} \mathrm{O}_{2}$ which is also detoxified by intracellular GSHPx enzyme.

Glutathione S-transferase is the one of the key enzymes that keeps the cellular membrane intact. GST which is also known as non-Se GsHPx is a part of antioxidant enzymatic system and plays a role in detoxification of lipid hydroxyl, peroxides (Prabhu et al., 2004). Glutathione S-transferase is localized in centrolobuler hepatocytes therefore, it is much more specific than ALT and AST for hepatic damage (Richard et al., 1992).

Glutathione S-transferase is known to be a more important marker for hepatotoxicity associated with volatile anesthetic agents. In the study of Schmidt et al. (1999) an elevation in GST levels was observed while ALT, AST and GGT did not change. Therefore, being a specific marker of hepatotoxicity and one of the cellular antioxidant enzymes, GST is important for free radical metabolism. Malondialdehyde is currently estimated by measurement of TBARS. In this study, TBARS levels

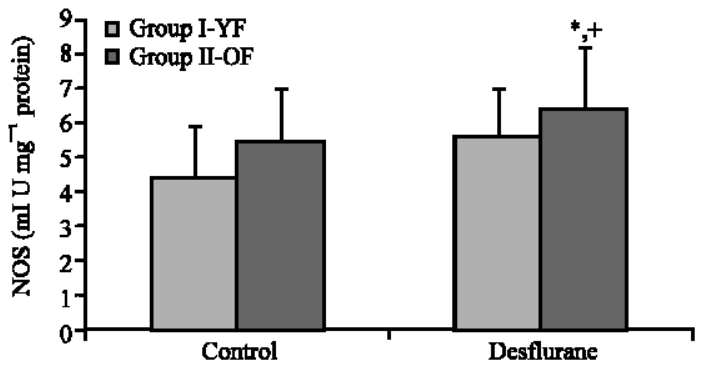

Fig. 4: The NOS levels of the groups. Values are mean $\pm \mathrm{SD} .{ }^{*} \mathrm{p}<0.05,{ }^{*} \mathrm{p}<0.05$, when compared to Group I- OFC, $+\mathrm{p}<0.05$ when compared to Group I-YFD

were studied as a marker of cellular membrane injury. TBARS is considered as a marker of lipid peroxidation injury via free radicals and it is assessed in studies evaluating the effects of volatile anesthetic agents (Bezerra et al., 2004). NOS level, however is a marker for assessment of the endothelial function of $O S$ (Wolin et al., 2005).

Briefly, it is possible to evaluate OS by studying TBARS and NOS levels and antioxidant defense systems based on superoxide levels such as SOD, GST in aerobic organisms (Allan et al., 1987; Richard et al., 1992; Sessa 1994; Prabhu et al., 2004). In the study, oxidant/ antioxidant effects of desflurane anesthetic agents were evaluated based on the levels of TBARS and enzyme activity of NOS, GST and SOD in the rat liver tissue samples.

There are some research showed that transient and significant increase of plasma GST level after desflurane anesthesia (Suttner et al., 2000; Tiainen et al., 1998; Rohn et al., 2005). Arslan et al. (2009) concluded that after desflurane anesthesia on patients were planned to undergo head and neck surgery, plasma GST level higher than preoperative measurement but it was not significant increase. Koksal et al. (2004) researched plasma malondialdehyde and SOD enzyme activity in bronchoalveoler lavage cell after the administration of desflurane or sevoflurane. Their results that plasma malondialdehyde increased more after the administration of desflurane than after sevoflurane and small but significant increase in plasma SOD concentration in Desflurane group. Consequently, Allaouchiche et al. (2001) showed that on rat desflurane administration elevated TBARS levels but not SOD enzyme activities. In similarly, Dikmen et al. (2007) showed SOD, GST enzyme activities and TBARS levels were significantly higher in anesthetized rat with desflurane than in control group. On the other hand, Kang et al. (1998) studied young and old female rats and found that antioxidant treatment was more effective in decreasing TBARS concentration in adult rats 
than it was in young rats. In addition, they reported that GST levels were lower in young rats than in adult rats. In the research, GST, SOD, NOS enzyme activities and TBARS levels were significantly higher in old female rat group than in young female rat group.

\section{CONCLUSION}

From this study, it can be concluded desflurane anesthesia caused more OS in aged rats. The study had some limitations. The first of these was the limited number of animals in each group. With higher number of animals, statistical significance would be clinically more important and provide more concrete evidence on the hepatic effects of these desflurane. Furthermore, the study was conducted on animals with spontaneous respiration and it was not possible to observe cardiovascular changes.

The higher rate of hepatotoxicity detected in old female rats implies caution in the use of desflurane in older female patients. Nevertheless, the injury caused by these agents was at a mild to moderate level which suggests that both can be used safely in regular everyday clinical practice. New clinical researches should be performed on large series.

\section{REFERENCES}

Allan, L.G., A.J. Hussey, J. Howie, G.J. Beckett, A.F. Smith, J.D. Hayes and G.B. Drummond, 1987. Hepatic glutathione $\mathrm{S}$ transferase release after halothane anesthesia: Open randomised comparison with isoflurane. Lancet, 329: 771-774.

Allaouchiche, B., R. Debon, J. Goudable, D. Chassard and F. Duflo, 2001. Oxidative stress status during exposure to propofol, sevoflurane and desflurane. Anesth. Analg., 93: 981-985.

Arslan, M., O. Kurtipek, A.T. Dogan, Y. Unal and Y. Kizil et al., 2009. Comparison of effects of anaesthesia with desflurane and enflurane on liver function. Singapore Med. J., 50: 73-77.

Arslan, M., Z. Ozkose, G. Akyol and G. Barit, 2010. The age-and gender-dependent effects of desflurane and sevoflurane on rat liver. Exp. Toxicol. Pathol., 62: $35-43$.

Berghaus, T.M., A. Baron, A. Geiger, R. Lamerz and G. Paumgartner, 1999. Hepatotoxicity following desflurane anesthesia. Hepatology, 29: 613-614.

Bezerra, F., A.A. Rezende, S.J. Rodrigues and M.G. Almedia, 2004. Thiobarbituric acid reactive substances as an index of lipid peroxidation in sevoflurane-treated rats. Rev. Bras. Anestesiol., 54: $640-649$.
Bucala, R., K.J. Tracey and A. Cerami, 1991. Advanced glycosylation products quench nitric oxide and mediate defective endothelium-dependent vasodilatation in experimental diabetes. J. Clin. Invest., 87: 432-438.

Carbonell, L.F., J.A. Nadal, C. Llanos, I. Hernandez, E. Nava and J. Diaz, 2000. Depletion of liver glutathione potantiates the oxidative stress and decreases nitric oxide synthesis in rat endotoxin shock model. Crit. Care. Med., 28: 2002-2006.

Chin, W.M., D.B. Njoku, G. MacQuillan, W.S. Cheng and N. Kontorinis, 2008. Desflurane-induced acute liver failure. Med. J. Aust., 189: 293-294.

Cote, G. and S. Bouchard, 2007. Hepatotoxicity after desflurane anesthesia in a 15 -month-old child with Mobius syndrome after previous exposure to isoflurane. Anesthesiology, 107: 843-845.

Dikmen, B., Y. Unal, H.K. Pampal, N. Nurlu and O. Kurtipek et al., 2007. Effects of repeated desflurane and sevoflurane anesthesia on enzymatic free radical scavanger system. Mol. Cell. Biochem., 294: 31-36.

Durak, I., H.S. Ozturk, B. Dikmen, C. Guven and M.Y. Cimen et al., 1999. Isoflurane impairs antioxidant defense system in guinea pig kidney. Can. J. Anaesth., 46: 797-802.

Durak, I., M. Kavutcu, M. Kacmaz, A. Avci and E. Horasanli et al., 2001. Effects of isoflurane on nitric oxide metabolism and oxidant status of guinea pig myocardium. Acta Anaesthesiol. Scand., 45: 119-122.

Durak, I., O. Canbolat, M. Kavutcu, H.S. Ozturk and Z. Yurtarslani, 1996a. Activities of total, cytoplasmic and mihochondrial superoxide dismutase enzymes in sera and pleural fluids from patient with lung cancer. J. Clin. Lab. Anal., 10: 17-20.

Durak, I., O. Kurtipek, H.S. Ozturk, M. Birey and T. Guven et al., 1997. Impaired antioxidant defense in guinea pig heart tissues treated with halothane. Can. J. Anaesth., 44: 1014-1120.

Durak, I., T. Guven, M. Birey, H.S. Oztürk and O. Kurtipek et al., 1996b. Halothane hepatotoxicity and hepatic free radical metabolism in guinea pigs: The effects of vitamin E. Can. J. Anaesth., 43: 741-748.

Eger II, E.I. and B.H. Johnson, 1987. MAC of I-653 in rats, including a test of the effect of body temperature and anesthetic duration. Anesth. Analg., 66: 974-976.

Habig, W.H., M.J. Pabst and W.B. Jokoby, 1974. Glutathione S-Transferases- The first step in mercapturic acid formation. J. Biol. Chem., 249: $7130-7139$ 
Haelewyn, B., L. Zhu, J.L. Hanouz, E. Persehaye, S. Roussel, P. Ducouret and J.L. Gerard, 2004. Cardioprotective effects of desflurane: Effect of timing and duration of administration in rat myocardium. Br. J. Anaesth., 92: 552-557.

Ignarro, L.J., G.M. Buga, K.S. Wood, R.E. Byrns and G. Chaudhuri, 1987. Endothelium-derived relaxing factor produced and released from artery and vein is nitric oxide. Proc. Natl. Acad. Sci. USA., 84: $9265-9269$.

Kang, M.Y., M. Tsuchiya, L. Packer and M. Manabe, 1998. In vitro study on antioxidant potential of various drugs used in the perioperative period. Acta Anaesthesiol. Scand., 42: 4-12.

Koksal, G.M., C. Sayilgan, S. Aydin, H. Uzun and H. Oz, 2004. The effects of sevoflurane and desflurane on lipid peroxidation during laparoscopic cholecystectomy. Eur. J. Anaesth., 21: 217-220.

Lowry, O.H., N.J. Rosebrough, A.L. Farr and R.J. Randall, 1951. Protein measurement with folin phenol reagent. J. Biol. Chem., 193: 265-275.

Martin, J.L., D.J. Plevak, K.D. Flannery, D. Charlton and J.J. Poterucha et al., 1995. Hepatotoxicity after desflurane anesthesia. Anesthesiology, 83: $1125-1129$.

Prabhu, K.S., P.V. Reddy, E.C. Jones, A.D. Liken and C. Reddy, 2004. Characterization of a class alpha glutathione-S-transferase with glutathione peroxidase activity in human liver microsomes. Arch. Biochem. Biophys., 424: 72-80.

Richard, M.J., B. Portal, J. Meo, C. Coudray, A. Hadjian and A.E. Favier, 1992. Malondialdehyde kit evaluated for determining plasma and lipoprotein fractions that react with thiobarbituric acid. Clin. Chem., 38: 704-709.

Rohn, K.D., S.W. Suttner, J. Boldt, T.A.H. Schollhorn and S.N. Piper, 2005. Insignifýcant effect of desfluranefentanyl-thiopental on hepatocellular integrity-a comparison with total intravenous anaesthesia using propofol-remifentanil. Eur. J. Anesth., 22: 209-214.
Schmidt, C.C., S.W. Suttner, S.N. Piper, D. Nagel and J. Boldt, 1999. Comparison of the effects of desflurane and isoflurane anaesthesia on hepatocellular function assessed by alpha glutathione S-transferase. Anaesthesia, 54: 1207-1211.

Schneemilch, C.E., T. Hachenberg, S. Ansorge, A. Ittenson and U. Bank, 2005. Effects of different anaesthetic agents on immune cell function in vitro. Eur. J. Anaesthesiol., 22: 616-623.

Sessa, W.C., 1994. The nitric oxide synthase family of proteins. J. Vasc. Res., 31: 131-143.

Suttner, S.W., C.C. Schmidt, J. Boldt, I. Huttner, B. Kumle and S.N. Piper, 2000. Low-flow desflurane and sevoflurane anesthesia minimally affect hepatic integrity and function in elderly patients. Anesth. Analg., 91: 206-212.

Tiainen, P., L. Lindgren and P.H. Rosenberg, 1998. Changes in hepatocellular integrity during and after desflurane or isoflurane anaesthesia in patients undergoing breast surgery. Br. J. Anaesth., 80: 87-89.

Tung, D., E.M. Yoshida, C.S. Wang and U.P. Steinbrecher, 2005. Severe desflurane hepatotoxicity after colon surgery in an elderly patient: [Severe hepatotoxicite au desflurane apres une operation du colon chez une patiente agee]. Can. J. Anaesth., 52: 133-136.

Van-Ye, T.M., A.M. Roza, G.M Pieper, J. Henderson, C.P. Johnson and M.B. Adams, 1993. Inhibition of intestinal lipid peroxidation does not minimize morphological damage. J. Surg. Res., 55: 553-558.

Wolin, M.S., M. Ahmad and S.A. Gupte, 2005. The sources of oxidative stress in the vessel wall. Kidney Int., 67: 1659-1661.

Xu, J., Y. Chang, B. Ouyang, Z. Lu and L. Li, 1998. Influence of isoflurane and sevoflurane on metabolism of oxygen free radicals in cardiac valve replacement. Hunan Yi Ke Da Xue Xue Bao, 23: 489-491. 